УДК 634.232:575.1/.2(479.24)

МОЛЕКУЛЯРНАЯ ХАРАКТЕРИСТИКА И ГЕНЕТИЧЕСКАЯ СВЯЗЬ
МЕЖДУ СОРТАМИ ЧЕРЕШНИ (PRUNUS AVIUM L.),
ОЦЕНИВАЕМАЯ С ПОМОЩЬЮ MАРКЕРОВ ISSR

Керимова Х.И.

Институт Генетических Ресурсов Национальной Академии Наук Азербайджана (НАНА), Бакy, e-mail: xayalakerimova90@gmail.com

Впервые в Азербайджане разнообразие сортов и форм черешни (Prunus avium L.) изучено с помощью 8 маркеров ISSR. В нашем исследовании для генотипов черешни была проведена реакция ПЦР с маркером ISSR на основе 8 ПЦР. Всего на 8 праймерах по изученным генотипам черешни было синтезировано 68 элементов, из которых 47 (69,1\%) были полиморфными, а 21 (30,9\%) - мономорфными. Количество амплифицированных локс фрагментов варьировало от 7 до 10. Диапазон длин полученных фрагментов варьировал от 100 до 1200 н.о. Количество пунктов на каждый праймер составляло 8,5 штуки. Наибольшее количество ампликонов (10 штук) было синтезировано с праймерами IS 50 и IS 54. Восемь ампликонов, синтезированных праймером IS 50, были полиморфными. В праймере IS 545 синтезированных пунктов были полиморфными, а остальные 5 - мономорфными. А наименьшее количество ампликонов отмечено в праймерах IS 3 и IS 48 (7 ампликонов). 4 ампликона в праймере IS 3 являются полиморфными. В праймере IS 48 из синтезированных пунктов 5 были полиморфными. Количество полиморфных пунктов варьировалось в пределах 4-8, в среднем 5,9 штуки. Для определения родственной связи между местными сортами и формами черешни в Азербайджане был проведен кластерный анализ на основе профилей ISSR и составлена дендрограмма. Генотипы сгруппированы в 8 основных кластеров. Индекс генетического сходства между образцами варьировал от 0,017 до 0,929 .

Ключевые слова: ISSR праймеры, молекулярные маркеры, Prunus avium L., кластерный анализ, генетическая связь

\title{
MOLECULAR CHARACTERIZATION AND RELATIONSHIP BETWEEN CHERRY (PRUNUS AVIUM L.) SORTS APPRECIATED BY ISSR MARKERS
}

\author{
Karimova K.I.
}

Genetic Resources Institute of ANAS, Baku, e-mail: xayalakerimova90@gmail.com

\begin{abstract}
For the first time in Azerbaijan, the diversity of cherry (Prunus avium L.) sorts and forms was researched with 8 ISSR markers. In our research work, a PCR reaction has been implemented with an ISSR marker based on 8 PCR for cherry genotypes. A total of 68 bands were synthesized on 8 primers in the researched cherry genotypes. $47(69.1 \%)$ were polymorphic and $21(30.9 \%)$ were monomorphic. The number of amplified fragments was between 7-10. The length range of the obtained fragments was between 100-1200 n.c. The number of bands for every primer is 8.5. Maximum number of amplicones (10) has been synthesized with IS 50 and IS 54 primers. Eight of the amplicones synthesized by the IS 50 primer were polymorphic. In the IS 54 primer, 5 of the synthesized bands were polymorphic and the other 5 were monomorphic. The lowest number of amplicons was observed in the IS 3 and IS 48 primers ( 7 amplicons). Four of the amplicones in the IS 3 primer are polymorphic. In the IS 48 primer, 5 of the synthesized bands were polymorphic. The number of polymorphic bands was between 4-8 and averaged 5.9. To determine the relationship between the local cherry sorts and forms of Azerbaijan, a cluster analysis has been implemented on the basis of ISSR profiles and a dendrogram has been compiled. Genotypes have been grouped into 8 main clusters. The genetic similarity index between the samples was $0.017-0.929$.
\end{abstract}

Keywords: ISSR primers, molecular markers, Prunus avium L., cluster analysis, genetic relation

В середине ХХ в. применение базовой молекулярной технологии, укрепление филогенетических связей, разработка генетических маркеров и построение связывающих карт развили наше понимание ключевых аспектов генетики Prunus [1]. Prunus avium - чтение его генома - было получено с использованием технологии секвенирования нового поколения (NGS illumina). Так, черешня (Prunus avium $\mathrm{L}$ ) общей длиной 41.294 Мб, содержащая ген кодирования белка 119.4 и повторяющиеся последовательности 43.9 Мб (272.4\%), была исследована. Развитие биотехнологии внесло инновации в последовательность генома, объединив методы секвенирования третьего поколения, технологии короткого чтения NGS с одномолекулярными последовательностями (Pacific Bioscience, Oxford Nanopore и Moleculo), способными считывать длиной до $50 \mathrm{~kb}$. Недавно геном дикой черешни был перечитан с использованием методик считывания длины Illumina и РасBio для сверхвысокого охвата (1265,6-кратной последовательности) и достиг длины генома 323,8 МБ с геном, кодирующим 43.349 белков [2].

Эти новые последовательности дают возможность определить генетическое разнообразие, которое все еще присутствует 
в диких видах Prunus, теряясь в продуктах в течение тысячелетий отбора и размножения. Эта геномная информация может использоваться, включая новые желательные аллели, для видов, культивируемых классическими или маркерными методами размножения (МАB).

Как и во всем мире, в нашей стране уже много лет ведутся работы по созданию коллекции с целью выявления генных запасов фруктовых сортов и отбора особей с превосходными характеристиками.

Выявление и защита генетических ресурсов наших растений так же важны, как и их богатство. Достижения в области биотехнологии в последние годы внесли значительный вклад в использование их генетических последовательностей для таких целей, как сохранение, производство, обновление, характеристика, разведение и развитие их разнообразия. При анализе методов, используемых для этой цели, видно, что это методы на основе ДНК, генетическая структура которых не меняется. Эти методы, называемые маркерами ДНК, обычно группируются как RFLP (Restriction Fragment Length Polymorphism), RAPD (Random Amplified Polymorphic DNA), SSR (Simple Sequence Repeats), AFLP (Amplified Fragment Length Polymorphism), SNP (Single Nucleotide Polymorphism), ISSR (Inter Simple Sequence Repeats). Среди перечисленных маркеров анализ ISSR считается одним из наиболее эффективных методов исследования генетического разнообразия и широко используется в сочетании с другими маркерными системами для определения полиморфизма в популяциях черешни. ISSR - это быстрый, простой метод с высокой повторяемостью, и радиоактивность не имеет значения при его использовании.

Идентификация черешни молекулярными методами в нашей Республике до сих пор не изучена. С нашей стороны была осуществлена морфологическая идентификация распространенных в Азербайджане форм дикой черешни и местных сортов и проведена их идентификация молекулярно-генетическими методами.

Изучение образцов черешни по молекулярным маркерам позволяет дифференцировать морфологические сходные образцы друг от друга и оценить степень генетической близости между генотипами.

\section{Материалы и методы исследования}

В качестве объекта исследования использовались местные и дикие сорта и формы черешни, собранные в Губинском, Хачмазском, Шекинском, Агдашском и Тертерском районах Азербайджана. В результате проведенных исследований было установлено, что в Губинском районе выращиваются 23 сорта черешни, в Хачмазском районе - 13, в Шеки - 26, в Тертерском районе -8 , в Агдашском районе - 4 .

Экстракция ДНК, относящаяся к генотипам, проводилась по протоколу СТАВ (cetyl-trimethyl-ammonium bromide), предложенному Роджерсом. Для измерения качества и количества ДНК использовали $1 \%$-ный агарозный гель и спектрофотометр ND-100 [3]. В реакциях ПЦР предпочтительно, чтобы показатель чистоты нуклеиновых кислот составлял 1,8-2,0. $81,1 \%$ использованных образцов черешни соответствовали этому результату. После проверки принадлежности ядерной ДНК к методу экстракции и эффективности этих ДНК для полимеразной цепной реакции были проведены маркерные анализы ISSR. Каждый образец разбавляли до концентрации 50 нг/мкл для ПЦР (полимеразная цепная реакция). ПЦР-смесь общим объемом $20 \mu 1$ (мкл) была приготовлена со следующим составом: $2 \mu 1$ 10x ПЦР-буфер, $2 \mu 1$ смеси dNTP (5 мМ), 1,5 $\mu 1$ $\mathrm{MgCl}_{2}(50 \mathrm{MM}), 2 \mu 1$ праймера (10 пмоль/ $\left.\mu \mathrm{l}\right)$, 0,2 мкл. Фрагмент одиночной полимеразы (1U/мкл) и 2 мкл геномной ДНК (50 нг/

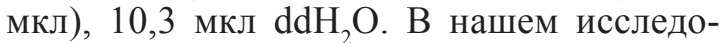
вании для генотипов черешни была установлена реакция ПЦР с 8 маркерами ISSR. Для ПЦР были выбраны следующие условия амплификации: начальная денатурация при $94{ }^{\circ} \mathrm{C}$ в течение 5 мин, денатурация при $94{ }^{\circ} \mathrm{C}$ в течение 1 мин на каждый цикл, комбинация в течение 45 секунд при различных температурах (в зависимости от праймера) и 35 циклов элонгации при $72^{\circ} \mathrm{C}$ в течение 5 мин; в конце - окончательная элонгация при $72{ }^{\circ} \mathrm{C}$ в течение 10 мин. Электрофоретический анализ продуктов ПЦР был проведен в 2\%-ном агарозном геле, гель был окрашен с добавлением бромида этидия и визуализирован под ультрафиолетовым излучением с использованием системы документации геля Bio-Rad.

Анализ амплифицированных фрагментов проводился с помощью компьютерной программы PAST (3). Для оценки генетического разнообразия в коллекции черешни был рассчитан ряд статистических параметров, в том числе индекс генетического разнообразия (ИГР (GMI)), полиморфная информационная емкость 
(PIC (ПИЕ)), эффективный коэффициент мультиплексирования (EMR (EKM)), индекс маркера (MI (ИМ)), мощность разделения (Rp), средняя мощность разделения (MRp). Оценка генетической близости между образцами и построение дендрограммы проводились на основе индекса генетического сходства Жаккар, а кластеризация проводилась методом UPGMA [4].

\section{Результаты исследования и их обсуждение}

В изученных генотипах черешни по 8 праймерам было синтезировано в общей сложности 68 пунктов, из которых $47(69,1 \%)$ были полиморфными, а 21 (30,9\%) - мономорфными. Количество амплифицированных локс фрагментов варьировало от 7 до 10. Диапазон длин полученных фрагментов варьировал от 100 до 1200 н.о. Количество пунктов на каждый праймер составляло 8,5 штуки.

Наибольшее количество ампликонов (10 штук) было синтезировано с праймерами IS 50 и IS 54. 8 ампликонов, синтезированных праймером IS 50, были полиморфными. В праймере IS 54 было 5 полиморфных синтезированных пунктов, а остальные 5 мономорфные. А наименьшее количество ампликонов отмечено в праймерах IS 3 и IS 48 (7 ампликонов). 4 ампликона в праймере IS 3 являются полиморфными. В праймере IS 48 полиморфными были 5 из синтезированных пунктов. Количество полиморфных пунктов варьировалось в пределах 4-8, в среднем 5,9 штуки.
Как видно из таблицы, показатель полиморфизма по праймерам колебался в пределах 50-89\%, средний полиморфизм составил $69,4 \%$.

Праймер UBC 868 ISSR показал самый высокий полиморфизм в генотипах черешни, будучи полиморфным в 8 из 9 зарегистрированных ампликонов. Полиморфизм составил 89\%. Длина ампликонов варьировала от 400 до 1200 н.о.

Иванович и другие изучили генетическое разнообразие 24 генотипов украинской черешни с использованием 8 праймеров ISSR. В анализе ISSR было синтезировано 193 ампликона. Уровень полиморфизма составил 75 \%. Исследование показало, что самый высокий уровень полиморфизма праймера UBC 881 ISSR составил 91,6\% [5].

Рогае Наджафзаде и другие провели исследование 12 генотипов черешни, выращенных в Иране, с использованием 23 праймеров ISSR. В результате было синтезировано 489 ампликонов. Среднее процентное соотношение полиморфизма по всем генотипам составило 98,45\%. Самый высокий полиморфизм отмечался в праймерах ISSR 6, 13, 14, 19 [6].

В ходе исследования был рассчитан индекс генетического разнообразия (ИГР) по каждому локусу ISSR. Средняя цена ИГР для изученной нами коллекции составила 0,92 ед. Высокие показатели составили 0,97 и 0,96 единицы для праймеров IS 50 и IS 2 соответственно. Высокая цена ИГР свидетельствует о богатом генетическом разнообразии сортов черешни из разных регионов Азербайджана.

Измерение полиморфизма и генетического разнообразия генотипов черешни с помощью праймеров ISSR

\begin{tabular}{|c|c|c|c|c|c|c|c|c|c|c|}
\hline Праймер & Последовательность (5'-3') & AOB & PBS & $\begin{array}{c}\text { PBF } \\
\%\end{array}$ & PIC & PIC & EMR & MI & MRp & GM \\
\hline IS 2 & $(\mathrm{GA})_{9} \mathrm{C}$ & 9 & 6 & 70 & 5,56 & 0,33 & 6,75 & 2,2 & 0,02 & 0,96 \\
\hline IS 3 & $\mathrm{G}(\mathrm{TG})_{9}$ & 7 & 4 & 57 & 7,46 & 0,41 & 4,1 & 1,6 & 0,02 & 0,85 \\
\hline IS 37 & $(\mathrm{CA})_{8} \mathrm{GT}$ & 8 & 6 & 75 & 5,00 & 0,33 & 5,6 & 1,7 & 0,03 & 0,94 \\
\hline IS 47 & $(\mathrm{ACC})_{6}$ & 8 & 5 & 62,5 & 6,30 & 0,41 & 5,6 & 2,3 & 0,02 & 0,91 \\
\hline IS 48 & $(\mathrm{ATG})_{8}$ & 7 & 5 & 71,4 & 5,16 & 0,43 & 4,2 & 1,7 & 0,03 & 0,93 \\
\hline IS 50 & $(\mathrm{GAA})_{6}$ & 10 & 8 & 80 & 7,34 & 0,45 & 8,0 & 3,6 & 0,01 & 0,97 \\
\hline IS 54 & $(\mathrm{AG})_{8} \mathrm{C}$ & 10 & 5 & 50 & 8,34 & 0,41 & 8,0 & 3,3 & 0,01 & 0,93 \\
\hline UBC 868 & $(\mathrm{GAA})_{6}$ & 9 & 8 & 89 & 4,46 & 0,32 & 6,8 & 2,0 & 0,03 & 0,89 \\
\hline Общий & - & 68 & 47 & & & & & & & \\
\hline Средняя цена & - & 8,5 & 5,9 & 69,4 & & & & & & 0,92 \\
\hline
\end{tabular}




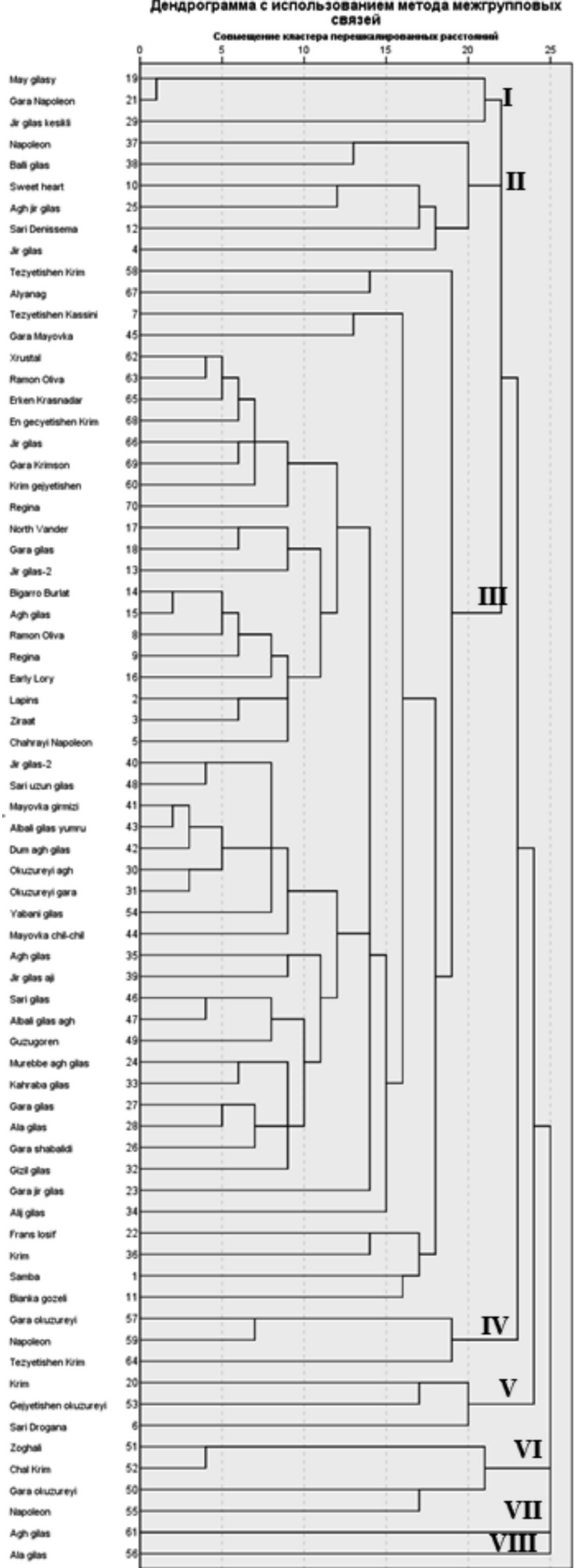


Известно, что для доминирующих маркеров, таких как ISSR, PIC варьируется в пределах 0-0,5. Для 8 праймеров, использованных в исследовании, РІС варьировался от 0,32 до 0,45 , в среднем 0,39 единицы. Наименьшее значение индекса РІС установлено для UBC 868, а максимальное значение - для праймера IS 50. Параметры MI и EMR являются ключевыми показателями информативности маркерных систем и рассчитываются отдельно для каждого праймеpa. В коллекции параметр МI варьировался от 1,6 до 3,6 , а EMR - от 4,1 до 8,0 , а средние значения составляли 2,3 и 6,1 соответственно. Праймеры с большим количеством полиморфных фрагментов характеризуются более высокими значениями EMR и MI.

Разрешающая способность (Rp) - параметр, определяющий дискриминационный потенциал праймеров. Для всех изученных локусов $\mathrm{Rp}$ варьировался от 4,46 до 8,34, средняя оценка составляла 6,2 . Среднее разрешение (MRp) варьировалось от 0,01 до 0,03 .

Для определения родственной связи между местными сортами и формами черешни в Азербайджане был проведен кластерный анализ на основе профилей ISSR и составлена дендрограмма. Генотипы сгруппированы в 8 основных кластеров (рисунок). Индекс генетического сходства между образцами варьировал от 0,017 до 0,929. Наибольшее генетическое расстояние было установлено между сортами Ала гилас (Агдаш) и Аг гилас (Шеки), индекс генетического сходства между указанными образцами составил 0,017 единицы. Наименьшее генетическое сходство наблюдалось между Албалы гилас и Сары гилас, выращиваемыми в Шеки, индекс генетического сходства между сортами составил 0,929 единицы.

Количество генотипов в кластерах варьировалось от 1 до 49, причем самый крупный 3-й кластер содержал в себе $66 \%$ генотипов. Кроме того, на дендограмме были идентифицированы 2 свободных кластера. Сорта Аг гилас и Ала гилас образовали свободные кластеры, что свидетельствует об их генетическом отличии от всех других экземпляров коллекции. Кроме того, было определено, что все 4 генотипа, включен- ные в 6-й кластер, состоят из сортов Тертер. Объединение этих разновидностей в один кластер указывает на то, что они имеют сходный набор аллелей в соответствии с изученными микросателлитными локусами. В то же время между некоторыми сортами из одного региона были обнаружены значительные генетические различия. Например, один из 3 сортов из одного региона находится во 2-м кластере Сары Дениссема, а сорта Регина и Early Lory pacположены в разных подкластерах одного и того же кластера, и индекс генетической дистанции между ними довольно высок 0,609 единицы.

\section{Заключение}

Таким образом, в результате изучения сортов и форм черешни из 5 различных регионов Азербайджана с помощью молекулярно-маркерной технологии подтверждена эффективность маркеров ISSR в оценке генетического разнообразия и генетического родства. Богатое генетическое разнообразие, обнаруженное в коллекции, свидетельствует о том, что Азербайджан является одним из центров выращивания черешни. Полученные результаты могут быть использованы при планировании будущих исследований по сбору генетических ресурсов черешни и в различных селекционных программах.

\section{Список литературы / References}

1. Arus P., Verde I., Sosinski B., Zhebentyayeva T., Abbott A.G. The peach genome. Tree Genet. Genomes 8. 2012. P. 531-547.

2. Baek S. et al. Draft genome sequence of wild Prunus yedoensis reveals massive inter-specific hybridization between sympatric flowering cherries. Genome Biol. 2018. Vol. 19. P. 127.

3. Rogers S.O., Bendich A.J. Extraction of DNT from milligram amounts of fresh, herbarium and mummified plant tissues. Plant. Mol. Biol. 1985. Vol. 5. P. 69-76.

4. Chung Nc., Miasojedow B., Startek M., Gambin A. Jaccard/Tanimoto similarity test and estimation methods for biological presence-absence data. BMC Bioinformatics. 2019. Vol. 20 (15). P. 644. DOI: 10. 1186/s12859-019-3118-5.

5. Ivanovych Ya.T., Udovychenko K.M., Bublyk M.O., Volkov R.A. ISSR-PCR Fingerprinting of Ukrainian Sweet Cherry (Prunus avium L.) Cultivars. Cytology and Genetics. 2017. Vol. 51. No. 1. P. 40-47.

6. Najafzadeh R., Arzani K., Bouzariand N. Ali Saei «Genetic Diversity Assessment and Identification of New Sour Cherry Gentyes Using Intersimple Sequence Repeat Merkers»» Hindawi Publishing Corporation International Journal of Biodiversity. 2014. Article ID 308398. P. 8. 